\title{
A VIOLÊNCIA OBSTÉTRICA E SUAS IMPLICAÇÕES NA SAÚDE MENTAL DA MULHER PARTURIENTE
}

\section{ARTIGO ORIGINAL}

CARDEAL, Érika Rayane do Amaral ${ }^{1}$, BRITO, Evelline Ferreira de ${ }^{2}$

CARDEAL, Érika Rayane do Amaral. BRITO, Evelline Ferreira de. A violência obstétrica e suas implicações na saúde mental da mulher parturiente. Revista Científica Multidisciplinar Núcleo do Conhecimento. Ano 06, Ed. 09, Vol. 05, pp. 2755. Setembro de 2021. ISSN: 2448-0959, Link de acesso: https://www.nucleodoconhecimento.com.br/psicologia/mulher-parturiente, DOI: 10.32749/nucleodoconhecimento.com.br/psicologia/mulher-parturiente

\section{RESUMO}

Esse artigo teve como objetivo geral analisar quais os impactos da violência obstétrica na saúde mental da mulher parturiente, à luz de uma perspectiva feminista dentro da psicologia, cujo instrumento metodológico para se chegar aos resultados foi a revisão sistemática de literatura. A natureza da pesquisa partiu de uma abordagem qualitativa, que utilizou 40 materiais das plataformas: SciElo, BVS, LILACS e PePsic. O estudo contemplou três subtópicos para as devidas discussões desse tema; a) o processo histórico do parir na sociedade atual através do feminismo, b) refletir sobre as relações de poder na hora do parto e, c) perspectivar como a psicologia tem se proposto a pensar estratégias de cuidado na violência obstétrica, sendo os três correspondentes aos objetivos específicos desta pesquisa e buscavam responder a problemática norteadora que é: Quais os impactos da violência obstétrica da saúde mental da mulher parturiente? Como ponto de partida deste trabalho, foi possível refletir sobre os movimentos e lutas históricas cravadas

\footnotetext{
${ }^{1}$ Graduação, especialização Psicologia Escolar e Educacional. ORCID: 0000-0002-3818-615X

${ }^{2}$ Graduada em Psicologia pela Universidade federal do vale do São Francisco - Univasf, em 2015, Especialização em Saúde mental com ênfase em Psicofarmacologia e Psicopatologia - INESP; Especialização em Sexologia Clínica ORCID: 0000-0002-6683-5516
}

RC: 97412

Disponível em: https://www.nucleodoconhecimento.com.br/psicologia/mulherparturiente 
por mulheres para conquistar seu lugar dentro da sociedade atual. Este texto também versa sobre os principais fatores sociais, culturais e religiosos que contribuíram e contribuem para o patriarcado dentro da sociedade contemporânea, mais especificamente dentro da instituição hospitalar; por parte da equipe, formada em sua grande maioria por homens e até mesmo mulheres, que reproduzem o discurso machista na hora do parto. Esse cenário configura assim, diversos tipos de violência, além da violência obstétrica, por parte das puérperas. Por consequência do acima citado, as mulheres vivem um parto que violam, além dos seus direitos reprodutivos e de dignidade da pessoa humana, também sofrem com a convivência com um corte na alma, na sua história e por fim, no seu corpo, se distanciando de um parto seguro, humanizado e principalmente, sem traumas.

Palavras-Chave: Violência Obstétrica, Direitos Reprodutivos, Puérperas, Psicologia, Feminismo.

\section{INTRODUÇÃO}

Atualmente, no Brasil, pouco se discute a violência obstétrica, principalmente na área da saúde, o que acarreta um desconhecimento por parte das vítimas e profissionais sobre práticas obstétricas danosas para as mulheres parturientes. Recentemente, um impacto foi causado pelo atual despacho do Ministério da Saúde, em maio de 2019 que corroborou com este cenário. De acordo com tal informação, o despacho desconsidera o termo que a Organização Mundial da Saúde (OMS) usa para caracterizar a violência obstétrica, a qual, era entendida como: o uso intencional de força física ou poder, em ameaça ou na prática, contra si próprio, uma pessoa ou um grupo que possa resultar em sofrimento (BRASIL, 2017).

Levando em consideração a decisão do Ministério da Saúde em tornar o termo e a sua conotação inadequada; automaticamente, o governo deslegitima um tipo de violência real, vivenciado em grande escala pelas mulheres brasileiras, negligenciando assim estas vítimas diárias. Embasados ainda, em um suposto saber exclusivamente médico em relação à mulher e o seu corpo, tornando-a submetida a

RC: 97412

Disponível em: https://www.nucleodoconhecimento.com.br/psicologia/mulherparturiente 
processos dolorosos, que resultam em danos físicos e psicológicos. Diante disso a violência obstétrica se perpetua e se naturaliza, configurando assim, um atentando a própria existência feminina e a uma maternidade sem traumas.

Portanto, como ponto de partida desta pesquisa retomaremos durante o estudo, a discussão sobre o uso do termo e a importância de citá-lo, para enfim, caracterizar o tipo de violência que afeta milhares de mulheres no sistema de saúde pública, a escolha desse público em especial foi devido a compreensão de que é nessa rede que acontece um atendimento aberto a todos que busquem o serviço, não negando a existência da violência obstétrica no setor privado. Visando a eficácia das informações repassadas a esta população, como uma proposta efetiva acerca da prevenção, considerando que a informação será sempre o melhor meio para se evitar o número crescente de casos de violência obstétrica. E diante da discussão, expor como a psicologia pode contribuir para tal prevenção e extinção da cultura violenta no meio obstétrico.

A principal motivação para sustentar a presente pesquisa, reside na relevância que o tema proposto possui para a sociedade, em específico para o público feminino. Considerando o tema de extrema importância para a sociedade contemporânea, capaz de possibilitar a compreensão de um tipo de violência pouco discutido e conhecido pelo próprio público-alvo e demais setores, e ainda pela incompletude das informações disseminadas nos serviços de saúde, o que causa um aumento no número de mulheres desconhecedoras de seus direitos reprodutivos, por conseguinte, violentadas diariamente.

Esta pesquisa permite a compreensão da importância de trabalhos produzidos por mulheres para mulheres, o que é o elemento-chave da epistemologia feminista; por isso, este estudo é uma confirmação da necessidade de a construção do conhecimento ser relacionada ao gênero, já que o fazer científico dos homens, é diferente de uma ciência produzida por mulheres. 
A partir deste estudo, foi possível relacionar a violência obstétrica aos impactos causados por ela na saúde mental da mulher; ambicionar a conceituação deste tipo de violência, e as relações de poder existentes neste contexto. Por fim, a pesquisa permitiu uma leitura contemporânea sobre o empoderamento feminino e o poder de decisão sobre o seu próprio corpo na hora do parto. Por essa razão, tornou-se essencial o desenvolvimento desta pesquisa a fim de atender uma necessidade já existente e localizada, porém, pouco explorada que é a incompletude e ineficácia das informações nos procedimentos acerca da temática.

Considerando então o que foi brevemente pontuado, a presente pesquisa voltou-se para a então problemática que é: Quais os impactos da violência obstétrica na saúde mental das mulheres parturientes? Dessa forma, discutiu-se as vivências das mulheres na hora do parto e a repercussão dessa dor não somente no puerpério, mas na qualidade de vida dessas vítimas. Para contribuição na compreensão destes fenômenos, o pensamento Heideggeriano foi focalizado, visando uma perspectiva de base existencialista.

Diante do então exposto, o presente trabalho teve por objetivo geral: compreender os impactos da violência obstétrica na saúde mental da mulher parturiente. E, ainda são objetivos específicos deste tema: a) Entender o processo histórico do parir na sociedade atual através do feminismo, b) Refletir sobre as relações de poder na hora do parto sob o corpo feminino e, c) Perspectivar como a psicologia tem se proposto a pensar estratégias de cuidado na violência obstétrica.

Em suma, surge a primordialidade de adentrar no atual contexto brasileiro em comparação com os tempos passados sobre o referido tema, para então compreender as características deste processo e as suas influências na vida das mulheres. Falar sobre a violência obstétrica inclui a mulher como única vítima deste cenário rotineiro, vivido por elas no processo de maternidade. Por isso, é preciso refletir sobre o momento histórico que perpassa por elas, o ambiente reforçador e após tudo isso, o acolhimento devido com as mesmas, perspectivando dentro do estudo o papel da psicologia no cuidado a priori.

RC: 97412

Disponível em: https://www.nucleodoconhecimento.com.br/psicologia/mulherparturiente 
Em síntese, será apresentado logo a seguir, os principais temas que subsidiam a temática deste, a metodologia com os critérios de inclusão e exclusão usados e que chegaram aos resultados e por fim, a apresentação desses resultados e as suas devidas discussões, organizados em três; sendo no primeiro subtópico as discussões relacionados a história da parturição no Brasil, o segundo subtópico se encontram as discussões alusivas a relação de poder e dominação do homem sob a mulher, mas especificamente na hora do parto, e por fim, o último subtópico que traz reflexões sobre as estratégias de cuidado com as puérperas e os seus bebês antes e após o parto, além da importância da inserção do psicólogo como profissional necessário dentro da equipe obstétrica hospitalar.

\section{REFERENCIAL TEÓRICO}

Para alcançar uma maior familiarização do leitor com a temática proposta, fez-se necessário adentrar em alguns conceitos básicos que se referem ao tema. Portanto, a princípio é importante iniciar com a conceituação da violência obstétrica. Goura (2018) considera violência na parição, toda e qualquer ação que possa constranger ou ferir física e/ou psicologicamente a mulher, a exemplo de: ter o atendimento negado ou dificultado durante o processo do parto, sofrer sucessivos exames de toques vaginais desnecessários e por profissionais diferentes em um curto espaço de tempo, não receber medidas analgésicas para aliviar dores, ou ainda, receber procedimentos sem ser consultada, sofrer contenção mecânica no leito, tolerar episiotomia[3] sem consentimento, ser insultada ou alvo de piadas durante o processo de parto e por fim, ser submetida à manobra de Kristeller[4]. São tamanhas as cicatrizes deixadas pelo parto mal assistido e violento, causadas nas mulheres. Segundo Dulce Ferraz (2016), um sentimento de solidão e desamparo nestes espaços que deveriam ser de cuidado e acolhimento.

Partindo deste conceito apresentado como violência obstétrica, faz-se necessário compreender a construção sociocultural do evento da dor, na experiência vivenciada por este público. Porém, não somente como fator biológico designado ao ser humano, mas na construção do parir com dor, nomeado então de purgação

RC: 97412

Disponível em: https://www.nucleodoconhecimento.com.br/psicologia/mulherparturiente 
feminina, que também é apresentado no Livro Bíblico de Gênesis 3:16, onde ele faz essa associação de um momento vivido por Eva, no qual a essência do texto traduz como um momento em que a mulher corrompe a humanidade após o ato sexual, ouvindo assim a expressão: "Aumentarei o seu sofrimento na gravidez e com muita dor darás a luz" (BARBOZA; MOTA, 2016).

Riechelmann (2012) coloca a dor como algo que ganha um sentido na vida da mulher, pois ele geralmente advém de uma experiência dolorosa, esse aspecto é fundamental para a compreensão da experiência do parto com dor ser aceito e ter um significado ao longo da vida da paciente. Assim sendo, a dor vai para além de um evento universal, ganha diante da sua construção e do seu sentir, aspectos que consideram a subjetividade do sujeito, revelando influências sociais, culturais, temporais e espaciais, bem como histórias de sofrimento intenso (OLY, 2010).

De outro modo, a construção da violência partindo do pressuposto sociocultural, se dá também de outra forma, a exemplo da construção machista ensinada a estas mulheres. Isto ocorre quando no discurso popular sobre o modo de se sentar feminino de pernas fechadas, sendo justificado como uma maneira para "manter o respeito sob si mesmo e pelo outro". Dito isso, e relacionando com o parir, essas mulheres se encontram agora no momento mais íntimo de suas vidas, recebendo sucessivos toques vaginais por diferentes profissionais, sendo obrigadas a manterem-se de pernas abertas por um longo período, frente a desconhecidos, cultuando um costume ilógico de que seus corpos são propriedade de outrem (BARBOSA; MOTA, 2016).

Visando esse cenário histórico, antes de qualquer coisa é preciso conhecer e caracterizar essa violência já mencionada, como uma violência institucionalizada, devido ocorrer em um órgão da saúde; o hospital, que tem por finalidade o acolhimento e o cuidado integral, no entanto, as relações de poder lá existentes acabam permitindo uma desigualdade. Por outro lado, também é apontada a precarização do serviço provenientes de frágeis condições de trabalho, tais como: 
despreparo dos profissionais para lidar com algumas questões, especificamente nas maternidades públicas que acabam comprometendo a relação profissional/paciente.

Sob outra perspectiva de análise dos fatos, estes profissionais não são somente agressores, mas também vítimas deste sistema, podendo citar inúmeros desafios enfrentados por eles no Sistema Único de Saúde, principalmente o repasse de verbas destinado à saúde, o que implica na: falta de médicos, superlotação das unidades de atendimento, acesso precário, falta de leitos hospitalares, assistência insuficiente, descaso com a saúde mental, e má distribuição dos profissionais de saúde (ALMEIDA, 2013). À vista disso, percebemos então as duas faces deste cenário e as implicações que acarretam a prática, esse profissional também pode ser percebido como uma vítima do sistema precário e assim se torna passivo ao adoecimento.

Deste modo, outro fator é necessário ser apontado, a hierarquização, na qual o topo é ocupado pela figura médica sendo a autoridade máxima do fazer técnico e científico. Consequentemente, adentra em uma relação de poder que permite uma desigualdade das partes envolvidas em que esse é destinado unicamente a um lugar de saber (AGUIAR; OLIVEIRA; SCHRAIBER, 2013). Na perspectiva de Isabela Ferreirinha e Tânia Raitz (2010), a melhor forma de compreender as relações de poder é buscar o significado da etimologia da palavra que advém do latim, tendo como significado "posse" ou "autoridade". Assim como no dicionário de Língua Portuguesa, que se encontra ligada diretamente a uma ação que exprime: controle, regulação e persuasão. Portanto, todas essas maneiras, se referem a poder como dispor de direito de agir e mandar (FERREIRA, 2001).

Para Wilza Pereira (2004), mesmo a mulher sendo neste cenário uma das grandes vítimas, pois além de sofrer violência institucional, devido os serviços que não funcionam a contento, também sofrem o que ele chama por violência do comportamento; já que está inserida em uma sociedade androcêntrica no modelo cartesiano[5] no sentido patriarcal, justificada pela dominação masculina. 
A violência institucional e simbólica nos serviços de saúde pública, apresentam modelos peculiares encontrados e enquadrados como gênese da violência institucional, que perpassam três fases: a não-informação, que se caracteriza como a informação não dada de forma proposital/consciente, por justificar que o outro não a compreenderia, devido ao seu grau de instrução; a segunda seria a informação negada, a qual é entendida como a informação procurada, porém não correspondida por diversas razões, mas que não atenderia o apelo do outro; e por fim, a informação fragmentada aquela que é reproduzida de diversas maneiras por diversos profissionais e quando dada a linguagem se apresenta de forma inacessível, pois é dotada de jargão técnico e profissional, o que impossibilita a compreensão dos pacientes sobre a real situação (PEREIRA, 2004).

As diferenças encontradas na assistência de saúde nas maternidades públicas e privadas, também são perceptíveis, uma delas é a manipulação do corpo feminino no que se refere a situação econômica da paciente. Ainda de acordo com a ideia de Pereira, a linguagem estabelecida na hora do parto, depende da situação econômica da parturiente, visto que, em maternidades privadas as mulheres estabelecem um outro grau de comunicação, maior e esclarecedor com o médico na hora do parto, além de outros cuidados básicos, a exemplo dos avisos prévios sobre interferências no seu corpo.

Por outro lado, ainda nas maternidades públicas as mulheres podem vir a sofrer do que Wilza Pereira (2004) chama por violência institucional, as características desta violência se dão por três fases, a primeira é: a uma generosidade intrínseca dos que precisam do serviço, porém não podem pagar, segundo: da manutenção de um monopólio dos saberes sob o corpo e as diferentes forma de intervi-lo e por último a desqualificação enquanto portador de um saber na área da saúde.

Por esse pressuposto, percebe-se ainda uma produção de sentidos por essas vítimas, uma vez que fazem analogia de quem manda e quem obedece, que neste segundo sentido será sempre aquele que necessita do serviço. Considerando que é a partir dessa lógica que se constrói significados e comportamentos, logo

RC: 97412

Disponível em: https://www.nucleodoconhecimento.com.br/psicologia/mulherparturiente 
diferenciam de quem cria o sentido, ou seja, o médico e é quem os interpretam. A saúde por sua vez, segue esse modelo, no qual identifica quem produz e quem o arbitra, o paciente e o médico. Acreditando que esse modelo segue o imaginário social, e cria a ideia de que as relações podem ser modificadas pelo outro, atrelando-as a quem detém o poder e tem o privilégio de legitimá-lo (PEREIRA, 2004).

Desta forma, é evidente o quão vítima é a mulher na hora do parto, e por isso, se cria todo um rito agudo nas instituições de exposição dos órgãos sexuais da mulher, podendo ser vistos, vasculhados, a frente de estranhos, levando-a a situações constrangedoras, o que acaba por validar novamente essa objetificação do corpo feminino nas práticas obstétricas e ginecológicas (PEREIRA, 2004). Considerando o exposto, a violência obstétrica, não inclui somente uma violência institucional e a relação de poder existente, mas ainda uma desigualdade de gênero. E, por este motivo, se faz necessário refletir sobre esse aspecto para uma maior compreensão do cenário de violência que as mulheres fazem parte.

Segundo Cristiane Souza (2015), a desigualdade de gênero segue uma linha histórica que perpassa a mulher por vários detrimentos. Talvez o maior deles, seja a construção familiar dada a essas mulheres ainda na infância, diferenciando assim, as atividades atribuídas a elas, direcionadas aos cuidados domésticos e maternos; em contraste, ao homem é dado o trabalho fora da casa. Permanecendo assim, a cultura machista e limitando a mulher ao confinamento doméstico, submissa às vontades dos homens em suas necessidades básicas, privando-as das próprias escolhas. Ainda para a autora, existe nessa construção, de um contrato, o que é nomeado e citado por; contrato social, o qual pressupõe um contrato sexual e matrimonial, mais necessariamente no sentido patriarcal, onde, socialmente, é criado o direito dos homens e da sociedade sob as mulheres, seus corpos e seus desejos.

A dicotomia existente como público e privado, denominado assim pelas influências sociais, como na essência do seu sentido; público devido a liberdade dada aos 
homens sobre os seus fazeres e desejos nos espaços; políticos, educacionais e sociais e privados as mulheres em seu confinamento doméstico e a família, que automaticamente foi se construindo com o passar do tempo. Essa lógica machista se perpetua, devido a algumas influências já citadas nos estudos de Cristiane Souza (2015) sobre os pensamentos da antiga filosofia, que acabam por possuir uma extrema relevância para compreendermos sobre a desigualdade de gênero atualmente, pois é a partir dessa dicotomia que percebemos o domínio masculino; em concomitante, conseguimos refletir sobre a exclusão das mulheres na maioria dos espaços e suas vontades.

Por outro lado, Martin Heidegger, dá uma nova opção de leitura do cenário e principalmente sobre o entendimento sob o humano (CASANOVA, 2015). O filósofo, busca compreender as várias facetas desse Ser em sua totalidade, como também o Ser com os outros, ou seja; o Ser aí ou até mesmo o Ser- no- mundo. O Ser lançado ao mundo sem o direito de escolhas de cenário ao qual almeja pertencer, seja ele: político, econômico e cultural, logo, por consequência disso, terá que se reinventar frente às suas vivências no tempo (HEIDEGGER, 2005).

Para além disso, há necessidade de refletir também sobre a ideia de cuidado para com essas mulheres, entrelaçado a uma desigualdade: social, econômica e cultural, quando não escolhem o cenário ao qual desejavam pertencer dentro do seu existencialismo, como já citado anteriormente. Toda essa conjuntura torna-as meramente um corpo sem história, sentimentos, um corpo que é tomado como objeto de estudo e não de subjetividade.

Leonardo Boff (2004) entende o cuidado, como um sentimento ético que há na essência do ser humano, porém, vai para além de um simples cuidar, o autor fala aqui de um modo de ser e o define como; o modo que a pessoa humana se relaciona com o mundo e seus iguais. O cuidado, implica no cuidar de si e do outro, permitindo assim, entrar em uma mesma sinergia (CARVALHO et al., 2003).

RC: 97412

Disponível em: https://www.nucleodoconhecimento.com.br/psicologia/mulherparturiente 
Boff (2004) acredita também que entramos, com o passar do tempo, em uma crise ética, o que implica na crise do cuidado, onde limitamos nossa visão no que transcende o outro afetando assim as relações. Mesmo nos pensamentos de Boff que trazem a ideia de ética e moral, é ressaltado que, atualmente o ser humano necessita de uma reeducação dos seus princípios, valores e, sobretudo, no que diz respeito ao cuidar, já que para o autor, ambos, são caminhos para o resgate da essência humana.

A reeducação do cuidar deve ser um hábito, revisto e reaprendido, pois, será por meio disso que o homem conseguirá conviver, aprendendo cuidadosamente ao tocar o outro com ternura e afeto; já que não existe a ideia do cuidado sem a presença do afeto, é através dele que nos tornamos sensíveis ao mundo e é por meio desse "deixar-se tocar", que nos constituímos enquanto ser humano e compreendemos as diferentes realidades, só a partir disso, conseguiremos mudar a nossa ótica (BOFF, 2004).

Por fim, para concluir a demonstração basilar da violência obstétrica, surge a necessidade de trazer às contribuições Feministas, que nos ajuda a entender também os temas subsequentes apontados neste estudo, tais como: violência institucional, violência simbólica, relação de poder, e desigualdade de gênero. Acredita-se que a leitura feminista poderá vir a contribuir sobre entendimento da urgência do empoderamento destas mulheres violentadas.

Segundo Conceição Nogueira (2001), o objetivo das várias teorias e movimentos feministas no decorrer do tempo, sempre foi pela plena igualdade de gênero, no entanto, o conceito sofreu no entendimento popular por várias definições, dando origem a diferentes posturas, que acabam confundindo a população sobre o seu objetivo geral. Mas, apesar de serem divididos historicamente em três ondas, os movimentos, em sua essência, traduzem um único sentido, a equiparação dos direitos para os gêneros.

RC: 97412

Disponível em: https://www.nucleodoconhecimento.com.br/psicologia/mulherparturiente 
Cada fase do feminismo, trouxe grandes contribuições para o que se refere a mulher contemporânea. Podemos citar brevemente cada uma das principais conquistas históricas, travadas por incessantes lutas, como por exemplo; a emancipação do estatuto civil da mulher, colocando-a como um sujeito jurídico, garantido os direitos básicos presentes na lei; a sua independência financeira, o que antes se restringia apenas ao lar e a maternidade como sendo suas únicas funções desenvolvidas na família; o controle da fertilidade, talvez nunca cogitadas na década de 70, com o surgimento das pílulas contraceptivas, surgiu também o empoderamento sexual feminino; entre outras conquistas, que tornam as mulheres oficialmente iguais perante a lei, direitos que não existiam em muitos países antes dos movimentos feministas (NOGUEIRA, 2001).

Portanto, se compreende que os pensamentos historicamente estereotipados para as mulheres, como um ser inferior por natureza, associada ao desejo do homem, sendo considerado na antiguidade a mulher como uma falha da espécie humana, atribuindo-as qualidades negativas sobre a sua existência, tem uma condição atrelada à consideração de que, o homem na maior parte do tempo foi criador da lei. Além do lugar da ciência, também masculinizada, acabou dando espaço para essas construções.

Conceição Nogueira (2001) afirma que houve um tempo em que no discurso médico, a mulher foi enfatizada como sendo unicamente um ser da esfera familiar, com um estatuto particular, legitimando um lugar dado a esta mulher na sociedade; o da maternidade e as vivências relacionadas à família e ao lar. Colocando-a novamente como submissa as vontades e desejos, daquele que detém de um poder sobre ela, o homem.

Por fim, compreendemos que a área de conhecimento do presente projeto de pesquisa é a psicologia. Como tema tratado dentro dessa ciência, se encontra a violência obstétrica, cujo o principal objeto de estudo são as mulheres vítimas deste cenário, retomando assim, esta discussão acerca do problema, de como esta violência pode influenciar no processo de manutenção da saúde mental da 
parturiente; e quais as possibilidades de intervenção da psicologia no combate e acolhimento a estas mulheres que sofrem.

\section{METODOLOGIA}

A princípio, se faz necessário antes de adentrar no caminho que foi percorrido, uma breve conceituação do que é metodologia científica, para então ser possível facilitar a compreensão acerca da função deste capítulo. Provanov e Freitas (2013) entendem por metodologia científica; o processo de estudar, compreender e avaliar, através de métodos e técnicas de pesquisas, que permitem a coleta de informações, visando a resolução ou explicação de questões em investigação, objetivando por meio disso, a construção do conhecimento.

Assim sendo, Liliane Zanella (2013) compreende por método, a forma escolhida para se ampliar o conhecimento sobre determinado fato, objeto ou fenômeno, sendo uma série de procedimentos intelectuais e técnicos para atingir determinado conhecimento a respeito de algo. Deste modo, a pesquisa é de base sistemática devido a busca minuciosa e investigativa sobre as principais teorias que norteiam o trabalho científico. MATTOS (2015) entende por revisão sistemática a investigação científica, sendo ainda um estudo de base analítica crítica, que tem como principal objetivo: levantar-se, reunir e avaliar criticamente os resultados obtidos.

É sabido que uma pesquisa para a sua validação, fidedignidade e confiabilidade requer critérios, bem como um caráter que possa norteá-lo, dessa forma o caráter da pesquisa em questão é explicativa, que visa conectar, identificar, compreender os fatores que determinam a ocorrência de um fenômeno (GIL, 2002).

A natureza da pesquisa partiu de uma abordagem qualitativa, a qual pode ser entendida como uma abordagem, que visa a compreensão de percepções e experiências, pensando em termos emergentes a discussão. Essa descrição não é expressa em termos numéricos (COZBY, 2003).

RC: 97412

Disponível em: https://www.nucleodoconhecimento.com.br/psicologia/mulherparturiente 


\subsection{REALIZAÇÃO DA PESQUISA}

Os termos de buscas adotados, foram as seguintes palavras: 1- história da parturição, 2- violência obstétrica, 3- relações de poder médico e, 4- psicologia puerperal, que são compatíveis com os objetivos específicos desta pesquisa. Por tanto, os termos de busca foram usados nas seguintes fontes: SciElo, LILACS, PePSIC e BVS, durante o processo de busca, foi usado o termo AND (os termos juntos durante a pesquisa) ao invés do OR (que significa um termo ou outro) para a obtenção dos dados.

A quantidade de fontes usadas teve como pretensão, proporcionar maior diversidade nos resultados apanhados. Ainda, pensou-se em plataformas com peso, que tivessem reconhecimento enquanto artigos científicos publicados, para garantir a confiabilidade e fidedignidade a pesquisa.

\subsection{CRITÉRIOS DE INCLUSÃO E EXCLUSÃO}

Os critérios de inclusão que foram usados na pesquisa são: idioma, que visou apenas os materiais publicados na língua portuguesa; ano de publicação no período entre os anos de 2010 a 2020, o longo recorte se justifica devido à falta de publicações de materiais, em especial na atualidade, por considerar um tema pouco conhecido e discutido.

Após incluir dados pelos critérios descritos acima, excluiu-se aqueles que não apresentaram afinidade com a temática, bem como, aqueles que não se encaixaram nos critérios de inclusão, que consequentemente não são compatíveis com os objetivos específicos da pesquisa. Outro critério usado para a coleta de dados, foi a partir da leitura dos resumos, que por fim, trouxe um respaldo maior quanto a aproximação do que almejou-se incluir ou descartar.

RC: 97412

Disponível em: https://www.nucleodoconhecimento.com.br/psicologia/mulherparturiente 


\subsection{CRITÉRIOS DE ANÁLISE DOS RESULTADOS}

A pesquisa objetivou uma análise dos resultados por meio de uma leitura de base Heideggeriana. Segundo Roehe (2006), a base analítica existencial permite que aspectos do conhecimento sejam questionados, quando não levam em consideração o modo de ser e a compreensão do contexto do sujeito. Como também se usou a epistemologia feminista para a interpretação e análise dos dados alcançados.

Segundo Haudrey Calvelli e Fátima Lopes (2011), a construção do conhecimento ocorre de maneira tradicional, que se remete apenas ao homem brancoheterossexual-civilizado-do-primeiro-mundo, não considerando as determinações culturais de um campo complexo de relações sociais, sexuais, étnicas e de gênero. Ainda as mesmas autoras, colocam as contribuições da epistemologia feminista para a construção do conhecimento, se fazendo possível abandonar a pretensão de conhecimento por parte de uma objetividade e neutralidade, para pensar então em um conhecimento que inclua as dimensões subjetivas, emocionais e intuitivas do conhecimento.

\section{RESULTADOS E DISCUSSÃO}

A princípio, foram analisados 40 materiais de diferentes áreas, incluindo a Psicologia como principal campo de pesquisa. As plataformas utilizadas foram a SciELO, BVS, LILACS e PePsic, coletados entre 29 de agosto de 2020 a 02 de setembro de 2020. Antes das discussões, é necessário levar em consideração algumas curiosidades despertadas durante a realização da pesquisa, como; notou-se durante o processo de busca, a escassez de materiais atuais na área da psicologia sobre a violência obstétrica, sendo a maioria desses resultados obtidos nas áreas de enfermagem e medicina. Esse foi o elemento-chave para uma reflexão sobre a importância de mais materiais publicados na psicologia sobre esse tipo de violência, incluída como a sexta violência contra à mulher, além da; física, matrimonial, psicológica, moral, sexual e patrimonial.

RC: 97412

Disponível em: https://www.nucleodoconhecimento.com.br/psicologia/mulherparturiente 
Por fim, um outro ponto para se dar ênfase é a violência obstétrica, como um problema que vai além de uma questão unicamente de saúde pública, adentramos agora na carência de estudos na área do direito, tendo como princípio os direitos violados na hora do parto.

\subsection{O PROCESSO HISTÓRICO DO PARIR NA SOCIEDADE ATUAL ATRAVÉS DO FEMINISMO}

A princípio como ponto de partida para a compreensão do processo histórico do parir, usou-se intencionalmente a palavra "parir" ao invés de parto ou nascer, como uma proposta provocadora de reflexão sobre a pronunciação e entendimento da palavra que remete ao parto a ideia de sofrimento para quem o vive, sendo uma base para a história do "parto ideal", medicalizado, e as suas devidas transformações históricas.

Segundo Fernanda Silvia et al. (2019), o parto atravessou linhas históricas que marcaram o fazer da obstetrícia e da ginecologia, como por exemplo; a transição da parteira para o médico, o parto realizado em casa para a instituição hospitalar, da doula $^{[6]}$ para a assistência da equipe e, mais ainda do processo natural do corpo, para a medicalização.

Tradicionalmente, o parto era realizado em domicílio, durante um longo tempo a rede de apoio das gestantes eram as figuras femininas que lhe acolhiam, as mães, vizinhas, irmãs, primas, tias e a parteira. $\mathrm{O}$ trabalho da doula consistia no auxílio no trabalho de parto, realizado unicamente pela mulher, também era de sua responsabilidade os cuidados com a casa, comida, higiene, e com o bebê após o seu nascimento assim como o período de recuperação da parturiente, chamado de resguardo ou pós-parto.

A transição da doula para o médico obstetra se deu devido a justificativa usada pela medicina sobre a "medicalização e higienização dos hábitos da população" (SILVIA et al., 2019). Justificativa essa que colocava em questão os saberes usados pelas

RC: 97412

Disponível em: https://www.nucleodoconhecimento.com.br/psicologia/mulherparturiente 
parteiras sobre o seu conhecimento adquirido na prática e a forma devidamente usada por elas em situações cuja mulher, não tinha condições alguma para realizar os seus partos em uma instituição hospitalar, já que os hospitais antigamente estavam distantes demais das suas condições financeiras, de acesso e mais ainda, de realidade.

Ainda para Fernanda Silvia et al. (2019), o argumento médico foi crucial para essa transição, colocando em pauta a idealização do hospital como lugar mais seguro para a realização de todos os partos, ainda como argumento se deu a parturição, como um evento demorado e doloroso demais para a mulher, por muitas vezes traumático. Essa discussão justificou a troca da doula para o obstetra e, do percurso natural para as intervenções médicas, na busca de um parto rápido, fácil e, "seguro", durante muito tempo e até mesmo atualmente, essa é a propaganda feita sobre o nascer.

Outro marco importante relacionado ao evento do parto assim como o pós-parto, foi conquistado a partir de longas discussões sobre a implementação do sistema de Alojamento Conjunto, onde objetivo principal era o vínculo da mãe com o recémnascido após o nascimento, esse sistema substituiu o antigo berçário, lugar que bebê ficava de forma separada de sua mãe nas primeiras horas de vida (TELES, 2016).

É, dessa forma que o processo minucioso de comparação pode ser feito, a partir de duas óticas, sendo a primeira na visão da doula, dando espaço para o contato desde o processo de parto até mesmo o pós, na criação e fortalecimento do primeiro contato com a criança; e a outra é a partir da visão medicinal, sobre a mulher passiva de intervenções, substituindo a sua autonomia e desejos sejam eles através do seu corpo ou escolhas, para o processo de medicalização.

De acordo com Samilla Nascimento et al. (2019), esse processo de mudança histórica não se deu de maneira tão aceitável pelas mulheres, devido a alguns significados criados por elas, como a angústia de serem retiradas do berço familiar

RC: 97412

Disponível em: https://www.nucleodoconhecimento.com.br/psicologia/mulherparturiente 
para a internação hospitalar, e o sentimento de incapacidade de gerir o seu próprio parto, quando vivenciada uma gestação que não oferecia riscos à mulher.

É importante ressaltar que não se está sendo questionada a importância do hospital enquanto instituição de saúde, mas o processo de medicalização do corpo feminino, visto quando se há necessidade dessas intervenções, pois o parto é perceptível como um evento natural do corpo e para além disso, a escolha da modalidade quando se é possível fazê-lo e que essa escolha seja feita por quem vive unicamente esse momento; as mulheres.

É justamente esse aspecto da "autonomia" no parto que os pensamentos das autoras Luciana Palharini (2017) confluente com o de Nathalia Rocha e Jaqueline Ferreira (2020) enfatizaram em seus estudos de cunho feminista, visualizando todas os discursos que rodeiam o processo de maternidade, e elas indagam sobre; "autonomia para quem?" na tentativa de elucidar as falas de médicos sobre a ideia de participação da mulher durante a arte de partejar.

Diante disso, além do distanciamento familiar, institucionalização e medicalização do corpo feminino já citados, mulheres que vivenciaram e vivenciam na atualidade intervenções sem a devida necessidade comprovada, apenas como forma de aceleração do parto. É neste cenário que emerge a violência obstétrica, entendida como atos de violência ao binômio mãe-bebê, que se caracterizam como maus tratos, sejam de ordem física, verbal, psicológica, manobras desconsideradas que venham a causar danos, da realização da cirurgia cesariana sem necessidade, ou qualquer procedimento que seja realizado sem o consentimento da mulher, configurando assim uma violação aos seus direitos sexuais e reprodutivos (NASCIMENO et al., 2019).

Autores como: Sônia Lansky et al. (2019), Priscyla Andrade et al. (2016), Juliana Sampaio et al. (2019), Sonia Giocomani e Olívia Hirsch (2020), Alice Gabriel e Breno Santos (2020), Gabriela Zanardo et al. (2017), Maristela Sens e Ana Stamm (2019), Jane Russo e Marina Nucci (2020), Jéssica Pauletti et al. (2019), Silvia 
Marques e Diego Nascimento (2019), Silvia Marques (2020), Patrícia Teixeira et al. (2020), Antônia Castro e Sibele Rocha (2020) percebem de modo geral a violência obstétrica como um corte que vai além do corpo, mas também na alma configurando cicatrizes que acompanham a mulher por toda a sua vida, e que é a partir dessa ótica de vê-lo e configurá-la enquanto violência, se estabelecendo a partir das transformações históricas, sociais e econômicas, que se torna possível um outro olhar da enfermagem e da medicina.

Como surpresa desse ponto, Ana Silva e Arnaldo Siqueira (2020) trazem grandes considerações sobre o descompasso no usufruto dos direitos, embora considere que existe portarias, legislações e decretos para o aperfeiçoamento nas políticas para a atenção obstétrica e neonatal, percebeu-se em todas elas que há uma ausência de mecanismos de responsabilização em casos de agentes de qualquer esfera, federal, estadual e municipal no que possa vir a violar os direitos garantidos no parto.

É esse um outro aspecto para se refletir sobre o aumento das incidências de casos de violência dessa natureza, e não somente como fator histórico, agora como algo que perpetua a mulher devido a sua falta de reconhecimento jurídico, e quando pensado sobre reconhecimento colocamos aqui a ideia jurídica não meramente como norte para os deveres, mas também o asseguramento dos direitos e as punições quando violados e qual figura os violam, e o peso que essa figura representa socialmente.

Todavia, percebe-se que esses processos com o passar do tempo têm sofrido uma reversão devido às influências dos movimentos feministas no olhar do judiciário, principalmente a partir da inserção de mais mulheres nesse poder, que rebatem com bastante ênfase o entendimento popular da subordinação por partes das mulheres a violência, pactuando da ilógica que é reproduzida socialmente entre gerações (BRITO et al., 2020.).

É a partir desse viés, que podemos trazer as variadas contribuições dos movimentos feministas, assim como a sua importância em diferentes espaços, com um novo 
olhar para problemáticas antigas arraigadas em uma cultura patriarcal. Outro ponto a ser destacado e que subsidia essa prática feminista, é o desenvolvimento de estudos, participações e contribuições feitas de uma minoria para outra, ou seja, mulheres tendo olhares para mulheres, por compreender ali uma representação social, gerando um sentimento de sororidade e equidade em diferentes campos de atuação, levando em conta aqui, o poder judiciário.

Os estudos de Joelma Souza et al. (2018) que dialoga com os de Francieli Carniel et al. (2019) trazem através de recortes de falas sobre a experiência de algumas gestantes sobre o seu processo de parto, em alguns recortes é possível perceber a violência obstétrica em pequenas ações, desde técnicas criminalizadas, até mesmo o tratamento.

[...] a experiência foi diferente da de agora [...] muito ruim! Porque o médico não teve tanta paciência. Ele [médico] me botou para ficar deitada, falou para botar força, como eu não tinha tanta força assim, ele deitou em cima de mim, invés de botar o braço na minha barriga para pressionar

para descer, ele botou o cotovelo, e aí ficou bem dolorido mesmo. Duas semanas dolorido. Ele ainda teve que me cortar, me cortou embaixo, levei pontos [...] eu tive aquele problema todo com os pontos. (E3) (SOUZA et al, 2018, p. 5).

Esse é um dos relatos de uma das entrevistadas por Joelma Souza et al. (2018) que traz o seu processo de parir, com o uso de técnicas usadas pelo médico, podendo essa ser entendida como a manobra de Kristeller, onde pressiona a barriga da gestante como forma de impulsionar a saída do bebê, técnica altamente agressiva e que foi criminalizada pelo Conselho Federal de Medicina e Enfermagem por compreender que a sua prática pode resultar em graves danos a mãe e a criança. Ainda, Francieli Carniel et al. (2019) como o corte no períneo para ampliar a passagem, resultando em um parto normal mais rápido, porém é necessário refletir sobre quando esse corte é uma necessidade e quando já é uma rotina.

Por fim, é importante enfatizar o recorte de fala de uma mulher que vivenciou esses momentos, já que este trabalho foi pensado e desenvolvido a partir de uma lógica feminista, que é; dar o lugar de fala a essas vítimas desse cenário que se configura

RC: 97412

Disponível em: https://www.nucleodoconhecimento.com.br/psicologia/mulherparturiente 
como um atentado a maternidade sem traumas. É pensado a partir dessa ótica, que se destaca a importância de ter a mulher como protagonista de seu parto e principalmente as escolhas dentro dele.

\subsection{REFLETIR SOBRE AS RELAÇÕES DE PODER NA HORA DO PARTO SOB O CORPO FEMININO}

É de fundamental importância e compreensão das relações de poder sobre o corpo, para correlacioná-los com a dominação na hora do parto. Segundo Cavalcante et al. (2014), as relações de poder em um determinado seguimento, a saúde, como um espaço em que impera o suposto saber, o que logo cria uma possível posição de quem manda e quem obedece, devido ao privilégio ocupado. Ainda para o mesmo autor, o poder, seja em qualquer esfera; educação, exército, especificamente na área da saúde, não pode ser visto unicamente como uma "coisa" nítida tão qual um objeto que se tem propriedade sob ele, mas sim como algo que é constitutivo nas interrelações (CAVALCANTE et al., 2014). É diante dessa breve perspectiva, que podemos entendê-lo a partir das relações e a sua manifestação na dinâmica de funcionamento do poder, compreendendo que o ele não se restringe unicamente a força física de Estado, mas para além disso, ele se constitui a partir da interação entre os indivíduos.

Para Foucault (1999) e Cirino (2018), existe uma aplicação do poder sobre o corpo humano, disciplinando as suas ações, para promover um aproveitamento máximo de suas capacidades, e assim, essas estratégias são usadas com um efeito de disciplina para a formação de indivíduos dóceis, obedientes, produtivos, rentáveis e, principalmente manipuláveis. Por esse viés, as relações de poder são compreendidas a partir de uma ação sobre outra ação, desmistificando a ideia de forte e fraco, mas sim de duas forças que se contrapõem e se interpenetram (FOUCAULT, 1999). Em outras palavras, o autor fala dos dispositivos que formam os mecanismos de poder, sendo mais profundo do que uma ideologia, mas sim todo um sistema de construção de símbolos, significados, repressão, e por fim de ideologia, que opera por muitas vezes como mecanismos de persuasão.

RC: 97412

Disponível em: https://www.nucleodoconhecimento.com.br/psicologia/mulherparturiente 
Diante dessa contribuição, percebem-se as relações de poder a partir das suas ramificações, em sua mais profunda forma de funcionamento, sem restringi-lo a um poder de Estado, mas também a partir de instituições que o coordenam em nome dele e se torna um campo para a sua manifestação, para maior enfatização; o poder ele é então um feixe de relações, e é a própria relação.

Segundo Tauana Silva (2018), as práticas em saúde também são permeadas por essas relações de poder. Em sua pesquisa a autora afirma que esse poder se dar através de duas formas, sendo a primeira delas entre os próprios profissionais da saúde, mais necessariamente entre os profissionais de outras áreas, e os da medicina, sendo esses considerados superiores, por uma construção histórica social, em relação ao modelo tradicional de doença-cura, e que era justamente o médico detentor desse poder sobre essa respectiva cura. Com o passar do tempo outras visões foram se criando, gerando um processo de mudança no que diz respeito a ideia de cura, assim como, a doença, necessitando da prática de outros profissionais na saúde, que permitiram outros modelos de atuação frente à prevenção, promoção e tratamento. Porém, à medida em que se teve essa inserção, também gerou conflitos, haja vista, que esses profissionais eram considerados subalternos aos médicos. Em segundo lugar, ocorreu a dominação do corpo assim como colocado pela autora, a dominação desse corpo objetal, fácil de ser manipulado, regrado e, passível (SILVA, 2018).

Neste caso é possível correlacionar as relações de poder a um fator histórico que se configurava nas práticas de saúde, assim como em outros espaços. Pode-se observar a submissão histórica de outros profissionais com os médicos, por serem considerados em sua prática, insuficientes ao modelo de cura, antes adotado, onde era visto apenas as manifestações do corpo sobre a doença, ou seja; os sintomas, e cura ideal era a ausência sintomática, desconsiderando o adoecimento advindo de outras ordens como psicológico, cultural e social. É, diante desse quadro que se avistou a necessidade de outros profissionais para ampliar a forma de tratamento. 
É nesse sentido que Gabriela Knorsts et al. (2019) destaca o contato dos pacientes com os médicos, na perspectiva de uma medicina em tempos passados, que o contato estabelecido com os pacientes, não era pensando no cuidado, acolhida e sim a sua devida atuação na cura frente à "crise". A autora traz também reflexões sobre a atualidade e a confrontação com esse poder, a exemplo disso é a internet, que trouxe um grande impacto nessa relação médico e paciente; pouco se fala a respeito desse impacto nas relações dentro das clínicas, incluindo na relação médico-paciente, e é exatamente esse fenômeno destacado pela autora, as possibilidades de mudança no modelo biomédico, essas introduzem discussões sobre o que seria o cuidado e qual é o papel dado nessa relação. A partir desses efeitos da tecnologia, torna-se possível questionar sobre o corpo e o processo de subjetividade, o encontro marcado pelo sentir e atribuir significado ao cuidado, bem como, o processo de dúvida sobre o médico que teme perder o controle da sua consulta ao paciente.

Dessa forma, são notórios os impactos que a internet teve nos papeis diante das relações, o que a autora traz como "impacto" é a busca realizada pelo paciente na internet sobre explicações para os seus quadros ou demandas, o que consequentemente afetou o modo de como se percebia a doença, o seu tratamento e ainda o cuidado; gerando inseguranças por parte dos médicos em como agir diante do paciente, e do paciente em como recebe os cuidados desse médico, estabelecendo um conflito de papéis.

Wilmar Silva (2011) realizou uma pesquisa para a compreensão das pacientes sobre o que elas entendiam por uma consulta ideal, separados através de recortes de falas a seguir.

A consulta ideal englobaria atenção ao paciente como indivíduo. Que o médico me olhe como um ser humano, não com uma coisa desprovida de sentimentos e emoções. Um médico educado, que saiba escutar, um médico que me ouvisse em primeiro lugar, o que é difícil encontrar hoje em dia. Ouvir a minha queixa, observando a minha linguagem e tentando me passar as informações médicas numa linguagem acessível. Alguns médicos só fazem discurso e não ouvem direito as queixas [...] Discurso coletivo 1 (SILVA, 2011, p. 211)

RC: 97412

Disponível em: https://www.nucleodoconhecimento.com.br/psicologia/mulherparturiente 
Nesse recorte de fala, é possível perceber alguns aspectos já mencionados no decorrer desse tópico. Trazendo em uma outra ótica a compreensão do modo de ser médico, também podemos incluir a sua própria formação acadêmica, estruturada a partir desse saber que repercute em sua atuação enquanto profissional. As relações de poder também estão presentes, a partir do momento em que é negado ou negligenciado ao paciente o direito a uma efetiva participação diante do seu próprio processo, por diversas razões, sendo uma delas a compreensão de que esse sujeito não precisaria dessa autonomia por não compreender a técnica.

Ainda, em no segundo recorte a seguir, algumas mulheres fazem indagações sobre a visão centrada no corpo:

[...] O médico deve analisar o paciente como um todo, não focar a atenção apenas no problema. O médico me escuta e busca o diagnóstico de forma holística. Um médico que me visse inteira, como um ser humano completo, e não por parte: curando um seio, um útero, um fígado...e sim, um corpo, com uma mente, com uma história [...] Discurso coletivo 2 (SILVA, 2011, p. 214)

Já nesse segundo momento, as mulheres colocaram indagações sobre a visão de alguns médicos, os quais focam apenas na doença, ou até mesmo no modelo doença-cura, o que consequentemente permite que elas se vejam resumidas a um órgão, desconsiderando outros fatores, como até mesmo a sua história, haja vista, que isso é a sua constituição enquanto sujeito.

Para maior aprofundamento direcionamos as relações de poder para o contexto de obstetrícia e ginecologia. Segundo Rejane Maudie (2018) a formação acadêmica também pode servir como um direcionamento para a solidificação dessas concepções de poder na prática, colocando o poder decisório do corpo da mulher em segundo plano, sendo apenas influenciado pelo processo de medicalização, prática comum nestas especializações. É pensando nessa atuação que se pode realçar a importância do processo de des(Construção) de práticas consolidadas, que visem a apropriação do corpo feminino em determinadas fases de sua vida, retirando-lhe o poder decisório. 
Ainda para Rejane Maduie (2018) essas práticas podem ser identificadas a partir de um conjunto de elementos, sendo eles; (1) O discurso de controle e vigilância, objetivando influenciar as mulheres por meio de discursos que apresentem formas "seguras" do parto, (2) a troca do poder da escolha das mulheres para o saber-poder profissional, que perspectiva na sua atuação, a anulação do conhecimento feminino sobre o seu próprio corpo e limites pessoais, (3) biopolítica da medicalização, elemento chave para se pensar no controle da mulher e de seu corpo, através de métodos medicamentosos, que "proporcionem" partos confortáveis.

Por fim, a face do poder agora se apresenta através de outra roupagem, por meio de discursos ofertados, de um falso cuidado ou que garantam um falso conforto a essas mulheres, que por muitas vezes estão disfarçados de meios que impossibilitam a autonomia dessas mulheres, frente ao seu processo de parto, por mais uma vez legitimar o saber técnico.

\subsection{PERSPECTIVAR COMO A PSICOLOGIA TEM SE PROPOSTO A PENSAR ESTRATÉGIAS DE CUIDADO NA VIOLÊNCIA OBSTÉTRICA}

A princípio faz-se necessário uma definição sobre estresse no parto e/ou pós-parto. Segundo Grazielle Noro e Márcia Gon (2015) o estresse funciona como uma resposta do organismo a uma situação externa estressora. As autoras, informam que o parto pode funcionar como um evento agressivo com repercussões na vida de quem os vive diretamente, sendo neste caso, a mãe e o bebê. Os efeitos no pósparto no binômio mãe-bebê, podem se repercutir para além do hospital, isso implica dizer que outras dimensões da vida desses sujeitos podem ser afetadas, como as relações afetivas, visão de mundo, constituição e entendimento de si próprio e pôr fim a própria fase de amamentação.

É pensando nesses impactos que Marina Favoro et al. (2012) e Luiza Abreu (2019) refletem sobre a qualidade de vida e os aspectos psicológicos por parte das gestantes no período puerperal. A princípio, as autoras dialogam sobre a produção de sentido que ocorre nos primeiros contatos entre o binômio, aqui elas trazem a

RC: 97412

Disponível em: https://www.nucleodoconhecimento.com.br/psicologia/mulherparturiente 
ideia de "imagem ideal", a qual se configura toda a dinâmica de idealização da criança, período de gestação, planejamento e sonhos para a chegada do bebê; e a "imagem real", como sendo esse o momento dessa chegada, seus impactos, o sofrimento, medo, angústia, insegurança, transformações externas no corpo externas e internas no processo hormonal.

Outro fator fundamental é sobre a própria ansiedade, que também é entendida como um estado emocional, resultante de um estímulo adverso (FAVARO et al., 2012). Sendo ainda, um desses desencadeadores as experiências vividas dentro do próprio hospital. É nesse sentido, que se ressalta a escassez de estudos na área da Psicologia Puerperal, que focalizem, sobretudo, a escuta e atenção durante esse processo de hospitalização.

Todas essas definições citadas anteriormente, para trazer o período gestacional e o seu pós, como eventos na vida da mulher que requer um olhar especial, atentando não somente para as mudanças externas, como a dinâmica e adaptação familiar, mas também a todos os sentidos que essa mulher possa está criando ao vivenciar essas fases, bem como a relação de adoecimento que pode estar sendo estabelecida. É justamente esse ponto, que Laís Boas et al. (2013) questiona sobre o espaço para uma escuta dentro do ambiente hospitalar para as futuras mães, já que se compreende durante o processo de fala, que conteúdos psíquicos possam ser elaborados, sendo ainda, um facilitador para a construção de sentidos sobre o lugar materno, a autonomia dessa mulher no parto e especialmente, a interação com o seu bebê.

Para maior ênfase na importância dessa escuta especializada do pré-natal até o pós-parto, Nathalia Tostes e Eliane Seidl (2016) desenvolveram pesquisas em algumas maternidades brasileiras com gestantes do primeiro trimestre até o último, a fim de enfatizar os anseios de quem vive a maternidade e como o profissional de psicologia pode estar presente nesses espaços, ecoados por fantasias, expectativas, medos, inseguranças e traumas, apresentados nos recortes de fala abaixo:

RC: 97412

Disponível em: https://www.nucleodoconhecimento.com.br/psicologia/mulherparturiente 
É medo do nascimento também, lá no hospital... Não sei, ninguém sabe se dá alguma coisa errada também... Eu tenho medo disso" (P14); "Tenho um medo de morrer na hora.... É porque a gente assiste muita televisão e vê tanta coisa acontecendo, aí eu fico com medo (P12) (TOSTES; SHEIDL, 2016, p.8).

Por meio desse pequeno relato de uma das entrevistadas, torna-se possível destacar a urgência de se ter o profissional da área de psicologia como parte integrante de uma equipe no período de pré-natal, fase de cuidado com o bebê, mas também com a gestante, levando em consideração as diversas influências, a fim de evitar que fatores psicoemocionais e ambientais possam interferir de maneira negativa no momento do parto. Por outro lado, também é importante falar a partir da perspectiva da mulher contemporânea; considerando que muito se foi falado sobre a perda da autonomia no processo de parto devido aos diversos modelos de interferência médica no corpo e nos desejos femininos. Porém, vale lembrar que o sofrimento causado devido à falta dessa autonomia, não se restringindo apenas a esse aspecto.

Aqui colocamos também o estilo de vida da mulher contemporânea, a qual ocupa diversos espaços, tais como a casa, família, trabalho entre outros, que compõe uma vida acelerada de atribuições, fruto de um processo árduo de lutas feministas que permitiram esses avanços. Mas, qual seria a relação do sofrimento no puerpério com a mulher contemporânea? Segundo Bruna Souza et al. (2013) a mulher contemporânea não está isenta do sofrimento psíquico durante o puerpério, já que a sua rotina também sofre um processo de adaptação para comportar seus sonhos, prioridades e metas estabelecidas por elas.

Assim, essa mulher com autonomia, mas acometida por diversas atribuições, sendo uma delas o processo de maternidade, mesmo com diversas discussões, ainda luta objetivando romper o modelo tradicional de que a mulher é suficientemente boa para a maternidade, tornando-se na maior parte das vezes responsável por ela. Sendo assim, o sofrimento e as dores do processo de maternidade também podem ser vistos por diversos ângulos, incluindo a perda da autonomia dessas mulheres no período puerperal, que ocorre, em média, por 120 dias, momento considerado de 
repouso após o parto, provocando um processo agudo de sofrimento, oscilação hormonal e outros adventos que merecem ser vistos e cuidados, considerando o evento, mas também suas lutas históricas.

Tagma Donelli e Rita Lopes (2013) falam da perspectiva de cuidado que atrelada ao trabalho do psicólogo no ambiente hospitalar, em especial dentro das maternidades, julgando ser a construção de uma ponte na comunicação, seja ela entre os próprios profissionais da equipe, e/ou entre a equipe e a gestante. Dessa forma, o psicólogo estariam no ambiente funcionando como intermediador/ facilitador de alguns processos, por levar em consideração na sua prática os fatores que permeiam o próprio ambiente, como o sentimento de desamparo, solidão, medo, a ideia de morte, doença/cura que estão arraigados na imagem do ambiente hospitalar e que interferem também no processo de relação entre gestante e a equipe.

As mesmas autoras destacam a urgência de se inovar no manejo dos aspectos emocionais com as parturientes, pois, no momento de crise, a sobrecarga emocional e na vulnerabilidade psíquica, bem como o surgimento de novas demandas que em contrapartida apresentam escassez de estudos relacionados a esse assunto, acarretando ainda um despreparo em relação aos futuros profissionais que possam a vir ocupar esses espaços (DONELLI; LOPES 2013).

Paula Komniski et al. (2017) e Vívian Rei et al. (2014) colocam como de suma importância o olhar da psicologia no que diz respeito os aspectos de organização psíquica após a chegada do bebê, além do devido suporte que esse profissional possa a vir oferecer, frente a essas novas vivências, que incluem a elaboração do luto sobre o filho imaginário[7], fase que ocorre na gestação com a idealização dos aspectos físicos da criança, já que esse ainda é desconhecido. Além disso, a possibilidade de ressignificar esse papel da maternidade, seus significados, afetações e desafios.

Por fim, se destaca a urgência de mais estudos desenvolvidos na área da Psicologia Puerperal como meio de promover o cuidado a saúde mental de mulheres gestantes 
antes e após o momento do parto, por levar em consideração as implicações físicas, psicológicas, biológicas, culturais e sociais dessa fase, que ainda sofrem influências de espaços permeados por fatores que limitam o ato de cuidar verdadeiramente do outro, de como ela se ver e se reconhece enquanto um ser diante da sua história.

\section{CONSIDERAÇÕES FINAIS}

Os resultados deste estudo reafirmam diversos fatores sociais e culturais que são provocadores do adoecimento das mulheres, cultuados através de um pensamento patriarcal, que estão presentes em diversos campos, como o próprio ambiente hospitalar. Em sua dinâmica de funcionamento traduz esse modelo juntamente com o de relações de poder, os quais fazem referência a submissão de uma parte sobre outra, desconsiderando a mulher como protagonista da sua história, vontade, desejos e mais especificamente do seu corpo na hora do parto, o saber feminino sobre ela, o mundo e o outro que é negado, sofrendo interferências tecnológicas agressivas, escondidas através de uma medicalização dos seus corpos.

Ainda, é possível levar em consideração os movimentos feministas que surgiram com uma proposta efetiva no que diz respeito à maternidade, colocando a mulher como protagonista de sua história, quebrando o conceito de "super-mãe" que limita essas mulheres apenas a um papel social dado a elas; a maternidade, desconsiderando outras vertentes como o próprio ato de ser e se reconhecer sujeito de vida, autonomia, que sente e experimenta diversos desejos incluindo os sexuais, suas fantasias, anseios e devaneios.

O parto é recheado de sentimentos e emoções adversos, mas que nenhum deles precisam ser justificados pelo saber e intervenção médica sem o consentimento de quem os vive e atribui sentido. Dessa forma, é que se mostra a importância da Psicologia como área de cuidado, acolhimento, visão do outro a partir de suas experiências e afetações, para proporcionar a autonomia dessas mulheres nesses espaços. Percebendo que as instituições de saúde também são compostas por afetações e que o deixar-se afetar pelo outro é parte crucial do processo de cuidado, 
pois é a partir dessa prática que se consegue atribuir sentido e valor a experiência em seu mundo.

Por fim, conclui-se que a violência obstétrica pode provocar marcas e traumas a saúde mental da mulher parturiente como o medo, insegurança, ansiedade, influências sobre a rejeição com o próprio corpo, bebê, amamentação, reconhecimento de si e entre tantos outros eventos que podem cercar o processo de maternidade após a violência.

\section{REFERÊNCIAS}

AGUIAR, Janaína Marques; OLIVEIRA, Ana Fávia Pires de Lucas; SCHRAIBER, Lilia Blima. Violência institucional, autoridade médica e poder nas maternidades sob a ótica dos profissionais de saúde. Cadernos de Saúde Pública, Rio de Janeiro. p. 2287-2296, nov, 2013.

ABREU, Ana Luiza Nunes. Significados e sentidos sobre o parto e nascimento dos participantes de uma exposição interativa. Dissertação (Mestrado em Enfermagem) - Universidade Federal de Minas Gerais. Belo Horizonte, 2019.

ANDRADE, Priscyla de Oliveira Nascimento et al. Fatores associados à violência obstétrica na assistência ao parto vaginal em uma maternidade de alta complexidade em Recife, Pernambuco. Revista Brasileira de Saúde Materno Infantil, Recife. v. 16, n. 1, p. 1-9, jan/mar, 2016.

ALMEIDA, Nemésio Dario. A saúde no Brasil, impasses e desafios enfrentados pelo Sistema Único de Saúde- SUS. Revista Psicologia e Saúde, Campo Grande. v. 5, n. 1, p. 01-09, jan/jun, 2013.

BRASIL, Ministério da Saúde. Despacho 9087621. Brasília, 3 de maio de 2019. Disponível

em:

$<$ https://sei.saude.gov.br/sei/controlador_externo.php?acao=documento_conferir\&co digo_verificador=9087621\&codigo_crc=1A6F34C4\&hash_download=c4c55cd95ede7

RC: 97412

Disponível em: https://www.nucleodoconhecimento.com.br/psicologia/mulherparturiente 
06d0b729845a5d6481d07e735f33d87d40984dd1b39a32d870fe89dcf1014bc76a32d 2a28d8f0a2c5ab928ff165c67d8219e35beb1a0adb3258\&visualizacao=1\&id_orgao_a cesso_externo=0 > Acesso em: 27 de fevereiro de 2020 .

BOFF, Leonardo. Ética e Moral. ำed. Petrópolis: Vozes, 2003, cap. 2: Genealogias da ética, p. 27-61.

BOAS, Laís Macêdo Vilas et al. Escuta Psicanalítica de Gestantes no Contexto Ambulatorial: uma experiência de grupos de fala. Psicologia, Brasília, v. 44, n. 1, p. 8-15, jan/mar, 2013.

BARBOZA, Luciana Pereira; MOTA, Alessivânia. Violência Obstétrica: vivências de sofrimento entre gestantes no Brasil. Revista Psicologia, Diversidade e Saúde. Salvador, p.119-129, mar. 2016.

BRITO, Cecília Maria Costa et al. Violência obstétrica e os direitos da parturiente: o olhar do Poder Judiciário brasileiro. Cadernos ibero-Americano de Direito Sanitário, Brasília, v. 9, n. 1, p. 120- 140, jan/mar, 2020.

CASANOVA, Marcos Antônio. Compreender Heidegger. $5^{\circ}$ ed. Petrópolis: Vozes,2015, cap. 2: Ontologia fundamental como analítica existencial: do ser ao tempo e do tempo ao ser, p. 75-140.

CALVELLI, Haudrey Germiniani; LOPES, Maria de Fátima. A teoria do conhecimento e a epistemologia feminista. Livros de anuais do congresso Scientiarum. Rio de Janeiro, v.1, n. 2. p. 347-353, jan, 2011.

CARVALHO, Enewton Eneas et al. O saber cuidar do ser humano: uma abordagem para o cuidado de enfermagem na perspectiva de Leonardo Boff. Revista de Enfermagem UFPE On line. Recife, p. 990-903, mar. 2003. 
CASTRO, Antônia Bezerra; ROCHA, Sibele Pontes. Violência obstétrica e os cuidados da enfermagem: reflexões a partir da literatura. Enfermagem em foco, Sobral, nov/fev, 2020.

CARNIEL, Francieli et al. Episiotomia de rotina: necessidade versus violência obstétrica. J. nurs health, Paraná, v. 9, n. 2, p. 1-18, abr, 2019.

CAVALCANTE, Ricardo et al. As relações de poder e a práxis informal em saúde. RECOM, Minas Gerais, v. 3, n. 4, p. 1382-1392, set/dez, 2014.

CIRINO, Oscar. Múltiplos corpos em Michael Foucault. Psicologia em Revista, Belo Horizonte, v. 24, n. 1, p. 302-317, abr, 2018.

COZBY, Paul C. Métodos de Pesquisa em Ciências do Comportamento. $1^{\text {a }}$ ed. São Paulo: Atlas, 2003, cap. 6: Observação do comportamento, p. 124-140.

DONELLI, Tagma Marina Schneider; LOPES, Rita de Cássia Sobreira. Descortinando a vivência emocional do parto através do Método Bick. Psico- USF, Bragança Paulista, v. 18, n. 2, p. 289-298, mar/ago, 2013.

FAVARO, Marina de Souza Filho et al. Avaliação do impacto da prematuridade na saúde mental de puérperas. Psico-USF, Bragança Paulista, v. 17, n. 3, p. 457- 465, set/dez, 2012.

FERREIRINHA, Isabela Maria Nunes; RAITZ, Tânia Regina. As relações de poder em Michael Foucault: reflexões teóricas. Revistas de administração Pública. Rio de Janeiro, p.368-383, mar/abr. 2010.

FERREIRA, AURÉLIO B. de H. Dicionário de língua portuguesa. Rio de Janeiro: Nova Fronteira, 2001. v. 4, p. 541.

FERRAZ, Dulce Aurélia de Souza. Resistir para experimentar parir: corporalidade, subjetividade e feminismo entre mulheres que buscam o parto humanizado no Brasil.

RC: 97412

Disponível em: https://www.nucleodoconhecimento.com.br/psicologia/mulherparturiente 
Interface- comunicação, saúde, educação. Botucatu, v. 20, n. 59, p. 1087-1091, out/dez, 2016.

FOUCAULT, Michel. Vigiar e Punir. $27^{\circ}$ ed. Petrópolis: Vozes, 1999. Cap. 1: Os corpos dóceis, p. 162-194

GABRIEL, Alice de Barros; SANTOS, Breno Ricardo Guimarães. A injustiça epistêmica na violência obstétrica. Revista Estudos Feministas, Florianópolis, v. 28, n.2, p. 1- 12, agos, 2020.

GIL, Antônio Carlos. Como elaborar projetos de pesquisas. $4^{a}$ ed. São Paulo: Atlas, 2002, cap. 4: Como classificar as pesquisas, p. 41- 56.

GIACOMINI, Sonia Maria; HIRSCH, Olívia Nogueira, Parto "natural" e/ou "humanizado"? Uma reflexão a partir da classe. Revistas Estudos Feministas, Florianópolis, v. 28, n.1, p. 1-14, mai, 2020.

GOURA, Mandato. Cartilha de Violência Obstétrica oficial. Maternidade simples. Curitiba, p. 1-10, nov, 2018.

GONZAGA, Doralyce; DUFFRAYER, Silvia. Nós somos mulheres. Disponível em: $<$ https://www.letras.mus.br/samba-que-elas-querem/nos-somos-mulheres/ > . Acesso em: 15 de outubro de 2020.

HEIDEGGER, MARTIN. Ser e Tempo. 15ํe ed. São Paulo: Vozes, 2005, cap. 5: o ser-como tal, p. 184-218.

KOMNISKI, Paula Cristina Nogueira Vieira et al. Encontros e desencontros: do nascimento à constituição do psiquismo. Estilos Clínica, São Paulo, v. 22, n.1, p. 113-131, jan/abr, 2017.

KNORSTS, Gabriela Rocha Santos et al. A relação com o médico na era do paciente expert: uma análise epistemológica, Interface comunicação, saúde, educação, Botucatu, v. 23, n. 18, 2019.

RC: 97412

Disponível em: https://www.nucleodoconhecimento.com.br/psicologia/mulherparturiente 
LANSKY, Sônia et al. Violência obstétrica: influências da Exposição Sentidos do Nascer na vivência das gestantes. Ciência \& Saúde Coletiva, Belo Horizonte, v. 24, n. 8, p. 1-14, agos, 2019.

MATTOS, Biblioteca prof. Paulo de Carvalho. Tipos de revisão de literatura. Faculdade de Ciências Agronômicas UNESP Campus de Botucatu, Botucatu, p.1-9, 2015.

MARQUES, Gabriela e Moreno; NASCIMENTO, Diego Zapellini. Alternativas que contribuem para a redução da violência obstétrica. Ciência \& Saúde Coletiva, Rio de Janeiro, v. 24, n. 12, dez, 2019.

MAUADIE, Rejane Araújo. 0 poder decisório da mulher no parto: as práticas discursivas dos profissionais e sua relação com a reforma obstétrica. Dissertação (Mestrado em Enfermagem), Universidade do Estado do Rio de Janeiro, Rio de Janeiro, 2018.

MARQUES, Silvia Badim. Violência obstétrica no Brasil: um conceito em construção para a garantia do direito integral à saúde das mulheres. Cadernos iberoAmericanos de direito sanitário. Brasília, jan/mar, 2020.

NASCIMENTO, Samilla Leal et al. Conhecimentos e experiências de violência obstétricas em mulheres que vivenciaram a experiência do parto. Enfermaría Atual de Costa Rica, Bahia, nov/abr, 2019.

NOGUEIRA, Conceição. Interseccionalidade e Psicologia Feminista. Salvador: Editora Devires, 2017.

NOGUEIRA, Conceição. Feminismo e Discurso do género na psicologia Social. Psicologia \& Sociedade: Revista da Associação Brasileira de Psicologia Social. Portugal, p.1-28, 2001. 
NORO, Grazielle; GON, Márcia Cristina Caserta. Epigenética, Cuidados Maternais e Vulnerabilidade ao Estresse: Conceitos básicos e Aplicabilidade. Psicologia Reflexão e Crítica, Porto Alegre, v. 28, n.4, p. 829-839, out/dez, 2015.

OLY, Lobato. O problema da dor. In: FILHO, Julio de Melo; BURD, Mirian. Psicossomática Hoje. 2º ed. São Paulo: Artmed Editora, 2010, cap: 17, p. 235-254.

PAULETTI, Jéssica Moré et al. Violência obstétrica: manifestações postadas em grupos virtuais no Facebook. Enfermería: Cuidados Humanizados, Pelotas, v. 9, n. 1, p. 1-18, jun, 2020.

PALHARINI, Luciana Aparecida. Autonomia para quem? O discurso médico hegemônico sobre a violência obstétrica no Brasil. Caderno Pagu, São Paulo, v. 17, n. 49, p. 1-37, mar/jan, 2017.

PEREIRA, Wilza Rocha. Poder, Violência e dominação simbólica nos serviços públicos de saúde. Texto \& Contexto- Enfermagem. Cuiabá, p. 391-399, jul/set. 2004.

PRODANOV, Cleber Cristiano; FREITAS, Ernani Cesar. Metodologia do trabalho científico: Métodos e técnicas da pesquisa e do trabalho acadêmico. $2^{\underline{a}}$ ed. Rio Grande do Sul: Feevale, 2013, cap. 2.4: Métodos de procedimentos- meios técnicos da investigação, p. 36-39.

RIECHELMANN, J. C.; Abordagem Psicossomática da Mulher Dolorida: A interface entre objetividade e subjetividade das dores de ser mulher. In: ANGERAMI, Valdemar Augusto Camon. Psicossomática e a Psicologia da dor. $2^{\circ}$ ed. São Paulo: CENGAGE Learning, 2012, p. 129-150.

ROCHA, Nathalia Fernanda Fernandez; FERREIRA, Jaqueline. A escolha de via de parto e a autonomia das mulheres no Brasil: uma revisão integrativa. Saúde em Debate, v. 44, n. 125, p. 556-568, abr/jun, 2020. 
REI, Vívian Anijar Fragoso et al. As dores do parto. Reflexões psicopatológicas em torno da angústia e do narcisismo primitivo. Estilos da Clínica, São Paul, v. 19, n. 1, p. 67-77, abr, 2014.

ROEHE, Marcelo Vial. Uma abordagem fenomenológica-existencial para a questão do conhecimento em psicologia. Estudos de psicologia, Natal, v.11, n.2, mai/ agos, 2006.

RUSSO, Jane A.; NUCCl, Marina Fisher. Parindo no paraíso: parto humanizado, ocitocina e produção corporal de uma nova maternidade. Interface Comunicação, Saúde, Educação, Botucatu, v. 24, n. 17, jan, 2020.

SAMPAIO, Juliana et al. Um corte na alma: com parturientes e doulas significam a violência obstétrica que experienciam. Revista Estudos Feministas, Florianópolis, v. 27, n. 3, p. 1-10, out, 2019.

SENS, Maristela Muller; STAMM, Ana Maria Nunes de Farias. A percepção dos médicos sobre as dimensões da violência obstétrica e/ou institucional. Interface Comunicação, Saúde, Educação. Botucatu, v. 23, n. 17, p. 1-16, agos, 2019.

SENS, Maristela Muller; STAMM, Ana Maria Nunes de Farias. Percepção dos médicos sobre a violência obstétrica na sutil dimensão da relação médico-paciente. Interface Comunicação, Saúde, Educação. Botucatu, v. 23, n. 10, p. 1-16, jul, 2019.

SILVA, Fernanda et al. "Parto ideal": medicalização e construção de uma roteirização da assistência ao parto hospitalar no Brasil em meados do século XX. Saúde e Sociedade, São Paulo, n. 3, v. 28, p. 171-184, jul/set, 2019.

SILVA, Ana Verônica Rodrigues; SIQUEIRA, Arnaldo Augusto Franco. Nascimento e cidadania: entre a norma e a política. Saúde \& Sociedade, São Paulo, n. 1, v. 29, p. 1- 12, mai, 2020. 
SILVA, Wilmar Madeira. Transformar é preciso: Transformações nas relações de poder estabelecidas entre médico e paciente (um estudo em comunidades virtuais). Tese (Doutorado em Saúde Pública), Faculdade de Saúde Pública da Universidade de São Paulo. São Paulo, 2011.

SILVA, Tauana Wazir Mattar. Configuração das práticas de saúde entre médicos e enfermeiros no ambiente hospitalar, na perspectiva das relações de poder. Dissertação (Mestrado em Enfermagem), Universidade Federal de Minas Gerais. Belo Horizonte, 2018.

SOUZA, Cristiane Aquino. A desigualdade de gênero no pensamento de Rousseau. Revista Novos Estudos Jurídicos, Ceará, v.20, n.1, p. 146-170, jan/abr. 2015.

SOUZA, Joelma Lacerda et al. Percepção de puérperas sobre a posição vertical no parto. Rev Bahiana Enfermagem, Bahia, v. 32, n. 27, p. 1-10, dez, 2018.

SOUZA, Bruna Moreira da Silva et al. O puerpério e a mulher contemporânea: uma investigação sobre a vivência e os impactos da perda da autonomia. Sociedade Brasileira de Psicologia Hospitalar, Rio de Janeiro, v. 16, n. 1, p. 166- 184, jan/jun, 2013.

TELES, Jéssica Machado. O ensino do parto e nascimento no curso de graduação em enfermagem nas décadas de 1970 e 1980. Dissertação (Mestrado em Enfermagem) - Universidade Federal do Rio Grande do Sul. Porto Alegre, 2016.

TEXEIRA, Patrícia da Costa et al. Percepção das parturientes sobre violência obstétrica: A que querem calar. Revisa Nursing, São Paulo, v. 261, n. 11, p. 36073615, fev, 2020.

TOSTES, Natalia Almeida; SEIDL, Eliane Maria Fleury. Expectativa de Gestantes sobre o Parto e suas Percepções acerca da Preparação para o Parto. Temas em Psicologia, Ribeirão Preto, v. 24, n. 2, p. 681-693, jun, 2016. 
TOLFO, Silveira; CÓRDOVA, Fernanda Peixoto. A pesquisa científica. In: GERHARDT, Tatiana Engel; SILVEIRA, Denise Tolfo. Métodos de pesquisa. $1^{\circ} \mathrm{ed}$. Rio Grande do Sul: UFRGS, 2009, p. 31-43.

ZANELLA, Liliane Carly Hermes. Metodologia de Pesquisa. $2^{\circ}$ ed. Florianópolis: reimpressa, 2013, cap. 6: observação do comportamento, p. 123-140.

ZANARDO, Gabriela Lemos de Pinto et al. Violência obstétrica no Brasil: uma revisão narrativa. Psicologia \& Sociedade, Porto Alegre, v. 29, n. 10, p. 1-11, jul, 2017.

\section{APÊNDICE - REFERÊNCIA NOTA DE RODAPÉ}

3. Corte feito na vulva da vagina para forçar a saída do bebê, geralmente esse procedimento é realizado sem medidas analgésicas.

4. Técnica criminalizada pelo Conselho Regional de Medicina, porém usada de forma a pressionar a parte superior do útero forçando a saída da criança, podendo causar danos graves à mãe e ao bebê.

5. Modelo que privilegia o saber masculino e a razão pura como método, método esse que faz referência a ideia de Descartes sobre a razão. No mais, o androcentrismo no modelo cartesiano seria a razão puramente masculina no sentido patriarcal, desconsiderando toda e qualquer forma de saber feminino, colocando o homem universalmente como o centro de toda construção de conhecimento.

6. Mulheres que fazem o parto sem técnica científica reconhecida pela medicina, no popular chamada de parteira. Responsável por se deslocar de suas casas para acompanhar a grávida e o seu bebê, antes, durante e após o trabalho de parto, compreendendo que seria essa a maneira ideal de cuidado.

RC: 97412

Disponível em: https://www.nucleodoconhecimento.com.br/psicologia/mulherparturiente 
7. Filho idealizado por a mãe ainda na vida intrauterina, seja em seus aspectos físicos quanto aos relacionais, na idealização do futuro, sonhos e em planos que são projetados no outro.

Enviado: Fevereiro, 2021.

Aprovado: Setembro, 2021. 